\title{
Application of Low-Cost Fixed-Wing UAV for Inland Lakes Shoreline Investigation
}

\author{
Tomasz Templin, ${ }^{1}$ Dariusz PopielarczyK, ${ }^{1}$ and Rafat Kosecki ${ }^{1}$
}

\begin{abstract}
One of the most important factors that influences the performance of geomorphologic parameters on urban lakes is the water level. It fluctuates periodically, causing shoreline changes. It is especially significant for typical environmental studies like bathymetric surveys, morphometric parameters calculation, sediment depth changes, thermal structure, water quality monitoring, etc. In most reservoirs, it can be obtained from digitized historical maps or plans or directly measured using the instruments such as: geodetic total station, GNSS receivers, UAV with different sensors, satellite and aerial photos, terrestrial and airborne light detection and ranging, or others. Today one of the most popular measuring platforms, increasingly applied in many applications is UAV. Unmanned aerial system can be a cheap, easy to use, on-demand technology for gathering remote sensing data. Our study presents a reliable methodology for shallow lake shoreline investigation with the use of a low-cost fixed-wing UAV system. The research was implemented on a small, eutrophic urban inland reservoir located in the northern part of Poland-Lake Suskie. The geodetic TS, and RTK/GNSS measurements, hydroacoustic soundings and experimental aerial mapping were conducted by the authors in 2012-2015. The article specifically describes the UAV system used for experimental measurements, the obtained results and the accuracy analysis. Final conclusions demonstrate that even a lowcost fixed-wing UAV can provide an excellent tool for accurately surveying a shallow lake shoreline and generate valuable geoinformation data collected definitely faster than when traditional geodetic methods are employed.
\end{abstract}

Key words: UAV, DEM, bathymetry, morphometry, GNSS, Lake Suskie.

\section{Introduction}

Water environment is a complex phenomenon, dynamic in both space and time. To understand its

The original version of this article was revised: the first name of the third author the small letter has been used instead to be capitalized. Furthermore the version of 'RAFAl' is incorrect. It should be 'RAFAE'.

1 Institute of Geodesy, University of Warmia and Mazury in Olsztyn, Oczapowskiego 1, 10-719 Olsztyn, Poland. E-mail: tomasz.templin@uwm.edu.pl nature a methodology that allows to accurately describe the objects and analyze the spatio-temporal changes is required. Over the years, different approaches have been employed to accurately model the topography of water reservoirs, lakes and rivers. They introduced new procedures, the processing chain, sensors, and algorithms (Popielarczyk et al. 2015).

The aquatic environment changes are the result of natural and anthropogenic forces, as well as the protection and restoration process of water reservoirs. The study of the state of this environment usually begins with a thorough analysis of the bathymetry and morphometry (Popielarczyk and Templin 2014; Lopata et al. 2014). The quality of morphometric parameters largely depends on the accuracy and quality of the collected data. One of the biggest challenges in the processing chain is the effective methodology to quickly and efficiently collect accurate and up-to-date data. To realize this idea the authors started a research program with the goal of developing a dedicated, open unmanned aerial system for semi-automated shallow water morphometric and bathymetric data acquisition.

Recent advances in surveying technology allow to construct a novel, automated measuring platform using modern sensors and processing algorithms. (Toth and Jóźków 2016). Traditional geodetic survey techniques (total station and RTK/GNSS surveys) are nowadays more frequently replaced with high-resolution laser sensors and semi-automatic platforms: aerial light detection and ranging systems (ALS), terrestrial light detection and ranging systems (TLS) or mobile light detection and ranging systems (MLS), personal laser scanning (PLS) (Marshall et al. 2016).

Water environment research usually requires continuous mapping of underwater and land topography. In most reservoirs, bathymetry can be measured with instruments such as sonar, single- 
beam echo sounder (SBES) or multi-beam systems (MBES) and bathymetric airborne LiDAR (International Hydrographic Organization 2005). Additional analysis of the adjacent topography requires remote sensing products like aerial photography, satellite images or radar imagery (Heine et al. 2015; Szostak et al. 2014; Szulwic et al. 2015).

One of the most important factors that influences the result of geomorphologic parameters on urban lakes is the water level. It fluctuates periodically, causing shoreline changes. The shape and length of the shoreline determine the bathymetry and morphometric parameters of the lake. It is especially significant for typical environmental studies like bathymetric surveys, sediment depth changes, thermal structure, water quality monitoring, etc. (Shintani and Fonstad 2017). In most reservoirs, the water level can be obtained from digitized historical maps and plans or direct measurements using: geodetic total station, GNSS receivers, satellite and aerial photos, and even UAV with different sensors.

Unmanned aerial vehicles (UAVs), known as drones, offer significant advantages in geodata collection and are a low-cost alternative to the classical manned aerial photogrammetry or complementary solution to terrestrial acquisition (Nex and Remondino 2014; Niedzielski et al. 2016). The greater coverage, better quality and resolution of affordable aerial platforms make the number of practical applications difficult to determine. UAVs increase speed and reduce the cost of remote data collection. Even a relatively small and cheap quadcopter, for example DJI Phantom, provides several minutes of effective working time/flight at working height up to 200-300 m above the ground. This allows measurements of small engineering objects in a limited terrain. A low-cost UAV equipped with remote sensors or camera allows frequent flights at low altitudes in almost any area (Huang et al. 2017).

The use of small unmanned measurement systems for acquiring geoscientific data has grown rapidly in recent years. Unmanned aerial vehicles (UAVs) are increasingly being used to monitor small areas, e.g., small water reservoirs (ponds, urban lakes) and can be a good alternative to satellites, due to better resolution and detail. UAVs have become significant tools to perform a photographic inventory of land and engineering structures. The most often used UAVs are low cost and not very sophisticated multicopters, which are becoming increasingly popular as a platform for photogrammetric cameras (Čermáková et al. 2016; Harvey et al. 2016; Yucel and Turan 2016).

In recent years, UAV platform has been developed to provide a solution for divergent water applications. Despite their increased capabilities, the use of drones in geophysical sciences is usually restricted to image acquisition for generating highresolution maps (Tauro et al. 2016). Some authors offered a solution-the use of UAV systems to reconstruct topography in coastal environment (Mancini et al. 2013), shallow braided rivers (Javernick et al. 2014) and lakes. More sensors will be developed over time allowing, for example, in situ measurements (Kageyama et al. 2016; Koparan and Koc 2016), pollution meters (Zang et al. 2012) and so on.

Only few researchers have addressed the problem of using fixed-wing UAVs in water studies (Everaerts 2008). They mainly concentrate on an advanced platform dedicated to the largest water reservoirs (Zolich et al. 2015). Most of the publications have been limited to off-the-shelf multicopters (AguirreGómez et al. 2016; Dietrich 2017). Despite the efficiency of such methods presented in the literature, their use is restricted to easy-to-access environments. They are limited in flight times and payload, with typical endurance of 15-20 min and payloads of up to $0.5 \mathrm{~kg}$ for consumer-level systems. UAV operation is also limited during windy weather conditions.

Due to their bigger size and more challenging service, fixed-wing platforms are considered as more complex, specialized tools. The main limitations are price, legal constraints and the need to ensure the technical expertise of the pilot. As a result, the UAV use usually requires cooperation with commercial companies (McEvoy et al. 2016). The application of the multi-rotor UAV in shoreline measurements is limited due to their range and working time. Therefore, the authors offer a much longer operation time of the measuring system by using the self-constructed and self-built fixed-wing unmanned aerial system (UAS), equipped with the autopilot and camera. A low-cost drone can operate for 35-40 min collecting photos for further elaboration. A properly configured 
autopilot can bring the sensor-equipped aircraft to the location where the measurements are to be made. After the surveys UAV can automatically return and perform a safe landing.

The study presents a reliable methodology for shallow lake shoreline investigation using a low-cost tailless fixed-wing UAV system. The research was implemented on a small, eutrophic urban inland reservoir located in the northern part of PolandLake Suskie. The geodetic TS, and RTK/GNSS measurements, hydroacoustic soundings and experimental aerial mapping were conducted by the authors in 2012-2015. The article specifically describes the UAV system used for experimental measurements, the obtained results and the accuracy analysis. The results show that even a low-cost fixed-wing UAV can provide an excellent tool for accurately surveying a shallow lake shoreline and providing valuable geoinformation data collected definitely faster than through traditional geodetic methods.

\section{Methodology}

The objective of any remote sensing (the process of measuring an object or phenomenon of interest from a distance), is to provide observation of some physical parameter in a mapping frame at a given time or time period (Toth and Jóźków 2016). Many studies have quantified analyzing the usefulness of UAVs for monitoring, inspection and surveys applications in water environment. Most of them are based on off-the-shelf constructions. Only few demonstrate advantages of an open, independent aerial platform (Sørensen et al. 2017).

A lot of research has been done using a different UAVs type platform. Using UAVs is now widespread across a range of disciplines (Anderson and Gaston 2013; Liu et al. 2014; Smith et al. 2016). The most popular environmental applications are: landslide monitoring (Lucieer et al. 2014a), measuring changes in coastal morphology (Casella et al. 2014; Gonçalves and Henriques 2015; Papakonstantinou et al. 2016), monitoring glacier movement (Immerzeel et al. 2014; Ryan et al. 2015), studying Antarctic moss beds (Lucieer et al. 2014b), soil erosion monitoring (d'Oleire-Oltmanns et al. 2012), fluvial geomorphology (Mori et al. 2002; Tamminga et al. 2015; Woodget et al. 2015) and forest research (Tang and Shao 2015; Wallace et al. 2012).

These studies are conducted using different UAV platforms delivered by various manufacturers (i.e., hybrid, flapping-wing, fixed-wing, coaxial, duct-fan, single rotor, and multi-rotor). Numerous documents in the literature describe the state-of-the-art development of UAVs (Cai et al. 2014). These reports provide a brief overview of small-scale unmanned aerial vehicles (UAVs) based on the information summarized from 132 models available worldwide. Their research was primarily concerned with the UAV platforms developed by academic institutions. Nowadays, there are also many complex commercial aerial mapping systems on the geodetic market. The review of UAS technology for photogrammetry and remote sensing applications with emphasis on regulations, acquisition systems, navigation and orientation can be found in the literature (Colomina and Molina 2014; Liu et al. 2014).

Recently, the most common platforms are multirotor and fixed-wing. Both have advantages and disadvantages which define their potential applications. Each UAV has a unique take-off and landing system (McEvoy et al. 2016). The fixed-wing systems require a larger clear area for both take-off and landing. They also need launching systems such as bungee cords or rails along with landing airbags, parachutes or nets (Gülch 2012). The multi-rotor model could take-off and land vertically from almost any location. Flight time and flight speed also vary between UAV models. The flight time for the fixedwing models was between 30 and 90 min per flight, whereas the flight time for multirotor models was usually less than 20 min per flight. It gives a wide area mission coverage within one basic package of battery. Fixed-wing UAVs move at a speed of approximately $15 \mathrm{~m} / \mathrm{s}$ while multi-rotor UAVs move at approximately $3 \mathrm{~m} / \mathrm{s}$. A fixed-wing body has better weather resistance, can be operated with stronger wind (up to $15 \mathrm{~m} / \mathrm{s}$ ) and during little rain (Haala et al. 2012). In case of minor damage, it allows for stable, continuous flight and safe landing. The fixed-wing platform is cheaper to build, has a simpler construction and fewer electronic components. The basic disadvantages of the wing are the need for open space 
for takeoff and landing and the need to be controlled by an experienced operator.

Considering the arguments above, the authors propose to build an open, low-cost unmanned aerial system (UAS) based on a popular fixed-wing Skywalker X-5 platform and the widely used open source flight control Pixhawk system with a dual processor, equipped with a global positioning system, data teletransmission module, etc. (Meier et al. 2012).

For economic reasons and payload restriction, the low-cost UAV platforms utilized for mapping purpose are mainly based on inexpensive passive sensors. A typical UAV imaging system consists of low-cost consumer-grade cameras. To obtain true ortho-photo mosaic and extract the 3D structure from multiple overlapping photographs, the structure from motion (SfM) algorithm is used. In most cases it is also combined with multi-view stereo (MVS) to automatically produce high-resolution digital elevation models (DEMs) (AgiSoft 2010; Snavely et al. 2008). This methodology is now well described and has been used in many studies (Fonstad and Marcus 2005; Wu 2013).

The growing popularity of aerial solutions increases the amount of flexible and scalable UAV software. New applications can automate navigation tasks and analyze the collected data. The photogrammetric SFM/ MVS software falls into two categories: commercial, proprietary software (easy to use, but closed like a black box) or open source software (more complex workflow that requires advance knowledge) (Shervais 2015).

To process data from a designed UAS platform different SFM/MVS software was considered. Open source applications like VisualSFM coupled with CMPMVS (Jancosek and Pajdla 2011) or SFMToolkit (Johnson et al. 2014; Westoby et al. 2012) were tested. Due to relatively early stage of our platform and certain limitations of these applications (maximum dimension of threshold, and others), the authors have decided to use one of the well-known, proprietary solutions-AgiSoft PhotoScan Pro from Agisoft.

\subsection{Study Area}

The presented research was implemented on a shallow, eutrophic inland reservoir. Lake Suskie is a small, urban lake located in the northern part of Poland (Fig. 1). It is situated in Susz Town, in the south-western part of Iławskie Lakeland, in the drainage basin of the Liwa River, a second-rank, east tributary to the Nogat River (Lossow et al. 2004). The lake is shallow with little-diversified bottom with max depth of 5.3 m (Choiński 2006; Inland Fisheries Institute in Olsztyn 1963). The lake has no natural surface inflows. The drainage basin on the eastern side is dewatered by melioration ditches. Heavily polluted 62-ha reservoir, located in the Iława Lake District, plays a significant role both in the water management of the Susz municipality and recreation for the region's inhabitants. The existing analog bathymetric plan of Lake Suskie and morphometric card had been developed by the Inland Fisheries Institute in Olsztyn (IRŚ) on the basis of historical measurements (Inland Fisheries Institute in Olsztyn 1963). Unfortunately, the historical analog bathymetric plan of the bottom shape and shore line differs from reality. The old bathymetry and morphometry were developed by the IRŚ in the previous century (in 1963).

\subsection{Work Purpose}

The main purpose of presented work is to reveal the potential application of the proposed tailless fixed-wing UAV platform and the data-processing chain within the case study of a typical shallow water reservoir.

The authors commissioned by the city of Susz regional authority have begun a study of Lake Suskie in the frame of a reclamation project. During the preliminary inventory of the lake, it turned out that the shape of the bottom and the course of the coastline differ significantly from those presented in previous morphometric data, adversely affecting the current morphometric data of the lake. In the years of 2012-2013, the authors have conducted new bathymetric surveys using dual-frequency, single-beam hydroacoustic system. The coastline has also been updated with TS and RTK geodetic techniques. However, classical shoreline measurement techniques have proved to be time-consuming and inaccurate because of the emergence of vegetation, wetlands and trees that adversely affect RTK/GNSS measurements. 


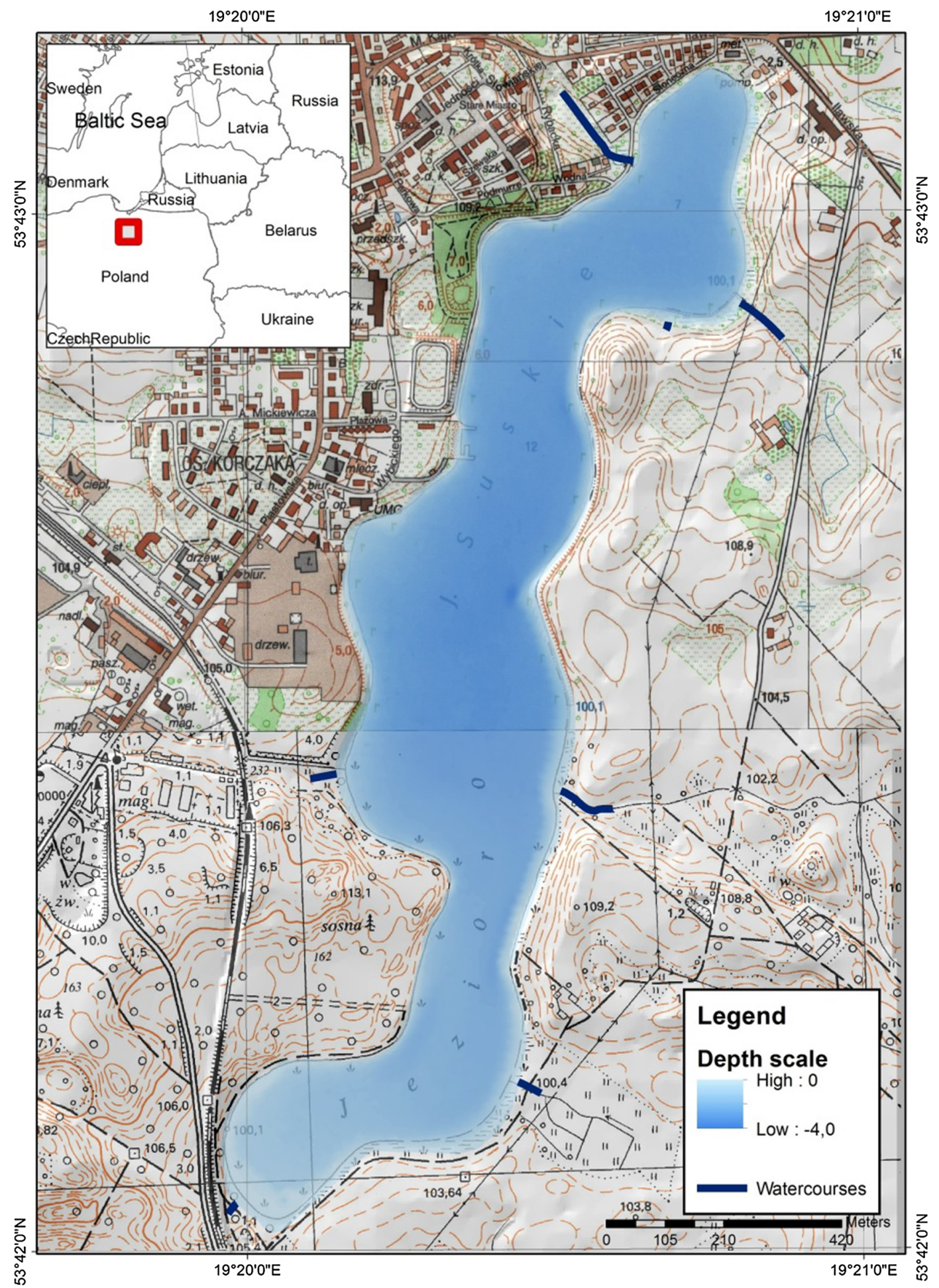

Figure 1

Location of Lake Suskie, the study area 
For this reason, the authors proposed the use of UAVs to inventory the shape of the coastline.

The proposed methodology for shoreline investigation and finally for bathymetry and morphometry calculation requires the integration of several measurements systems. Direct geodetic, GNSS, hydroacoustic and finally proposed aerial measurements are used to quickly and reliably collect accurate data. The new challenge was to implement a modern, low-cost and efficient UAV system that supports an effective collection of shoreline data across large areas of the water environment.

Figure 2 shows the proposed procedure and lists the methods of coastline extracting used during the experimental study and further analysis. At first, potentially useful methodologies for shoreline acquisition were analyzed. The available data sources were discovered and used (the bathymetric plans and morphometric cards, aerial photos and satellite images, topographic maps and cadastral data from existing databases). Then direct geodetic, bathymetric and aerial measurements were conducted and the collected data were processed to calculate shoreline changes. The extracted shorelines were compared. Finally, the chosen UAV shoreline was applied to elaborate up-to-date bathymetry and morphometry of the lake.
The potential influence of data acquisition methodology and changes between different method results was presented on the most characteristic, east part of the lake shoreline (Figs. 2, 4). To highlight the advantages of the UAV system, the comparison between different measurement techniques was discussed. The results from the unmanned aerial platform were assigned and compared with complementary techniques and classical TS and GNSS methods of coastline detection on shallow reservoirs. The optimal solution was chosen for new bathymetric elaboration and new morphometric parameters calculation. A reliable Digital Elevation Model of the lake bottom was made and processed in the following steps. At the end, the results of the bathymetric campaign were discussed. The presented methodology was proposed to be applied during a sediment and morphometry analysis task on the typical small, eutrophic urban inland reservoir (Lake Suskie).

\subsection{Geodetic/Bathymetric Data Collecting and Processing}

According to the Lake Suskie reclamation project, new bathymetric surveys were conducted to elaborate up-to-date bottom elevation model and to calculate morphometric parameters. The integrated

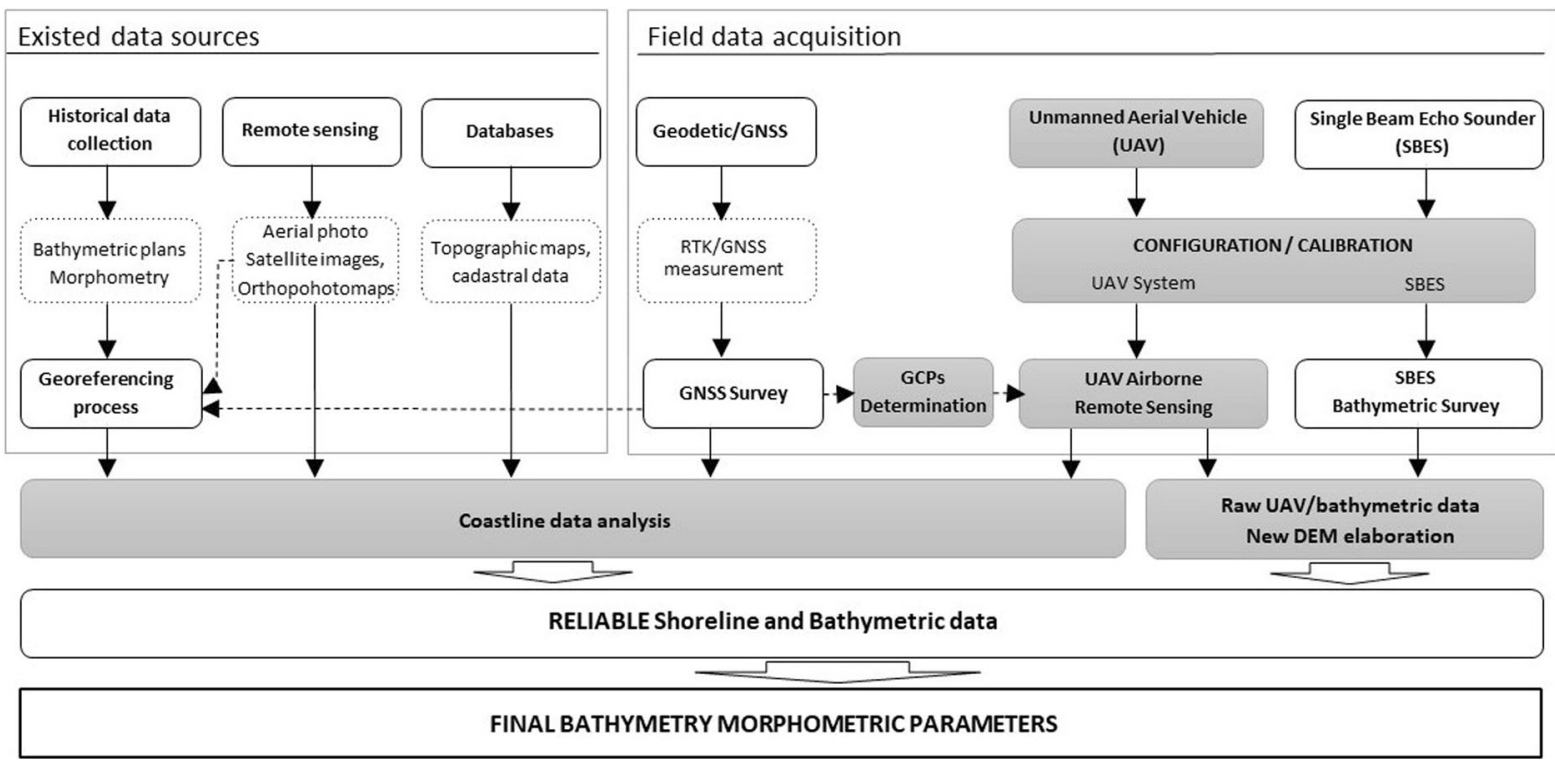

Figure 2

Flowchart of the adopted methodology 
bathymetric system used during depth measurements basically consists of: RTK/GNSS positioning, an SBES hydroacoustic bottom detection system and special GNSS, hydrographic and GIS software. During the project, Topcon Hiper Pro receivers were used and RTK/GNSS positioning was completed based on the Ground-Based Augmentation System (GBAS) permanent reference station ASG-EUPOS (Active Geodetic Network-EUPOS). Additionally, the raw GNSS/static/data were used for accurate water level calculations. The hydrographic SBES equipment included two single-beam digital hydrographic Echo Sounders: a Simrad EA501 P and a Reson Navisound 515. Additionally, a YSI 600R sonde for SBES calibration was used. The EA $501 \mathrm{P}$ system basically consists of a $200-\mathrm{kHz}$ transducer, transceiver and personal computer. Dual channel Navisound 515 uses two-frequency transducers (38 and $200 \mathrm{kHz}$ ). The bathymetric measurements were carried out in two stages. The first part covered the central deepest region of Lake Suskie. The second was conducted in the northern and southern part of the lake. The basic measurement profiles were designed in the east-west direction at spatial sampling of $10 \mathrm{~m}$. After conducting all the stages of field measurement campaign on Lake Suskie, the bathymetric raw data were processed.

\section{UAV Measurements}

The last element necessary for the development of the current bathymetry and morphometric data was the updating of the shoreline course. For this purpose, the authors propose a new methodology for the coastline shape inventory with the use of UAV. The whole area of Lake Suskie covered by scheduled and executed experimental aerial measurement was divided into four basic parts/flights. In the present work the most interesting middle/east part of the lake was presented and analyzed (Fig. 4).

\subsection{UAV Fixed-Wing Prototype}

Lake shoreline measurements and the inventory of underwater vegetation as well as adjacent areas cover large areas and take considerable time. That is one reason why the authors have built their own prototype of unmanned aerial system (UAS) based on Skywalker X-5 fixed-wing platform.

The proposed UAS consists of five main components:

1. Unmanned aerial vehicle (UAV).

2. Sensor (camera).

3. Radio control system (RC).

4. Telemetry link.

5. Ground control station (GCS).

7A tailless fixed-wing aircraft is made of expanded polyolefin (EPO). The UAV is based on separate components available on the market, in hobby stores. All individual components have been purchased, configured and finally calibrated by the authors (Table 1). In addition to a simple based platform, it also contains radio control, telemetry and autopilot systems, GNSS positioning and a high torque brushless motor. The heart of the drone is an open source autopilot called Pixhawk and peripheral sensors, i.e., a GPS receiver with magnetometer, Pitots' tube, servo motors, an electronic speed controller with a brushless engine. Pixhawk works with Ardupilot firmware, which provides full automatic flights and camera triggering. Frsky's transmitter Taranis is a radio control (RC) system used as the safety background for steering of the drone. It makes it

Table 1

Basic technical specifications of flying wing UAV system

\begin{tabular}{ll}
\hline Characteristics & UAS parameters \\
\hline UAV type & $\begin{array}{c}\text { Tailless fixed flying wing “Skywalker } \\
\text { X-5" }\end{array}$ \\
Wingspan & $1180 \mathrm{~mm}$ \\
Total mass & $1.35 \mathrm{~kg}$ \\
Autopilot & PixHawk v2.45 \\
Radio control & FrSky Taranis X9D PLUS \\
Engine & High torque brushless motor AXI 2808/24 \\
& Gold \\
Camera & Sony RX100 20 MP, with Seagull \\
& controller \\
Battery life & $45 \mathrm{~min}$ (LiPo 3S, 11.1 V, 4600 mAh) \\
Max. flight time & $40 \mathrm{~min}$ \\
Max flight speed & $18 \mathrm{~m} / \mathrm{s}$ \\
Max. wind speed & $15 \mathrm{~m} / \mathrm{s}$ \\
Min. flight altitude & $70 \mathrm{~m}$ above ground level \\
Telemetry and RC & Up to 2 km \\
range & \\
\hline
\end{tabular}




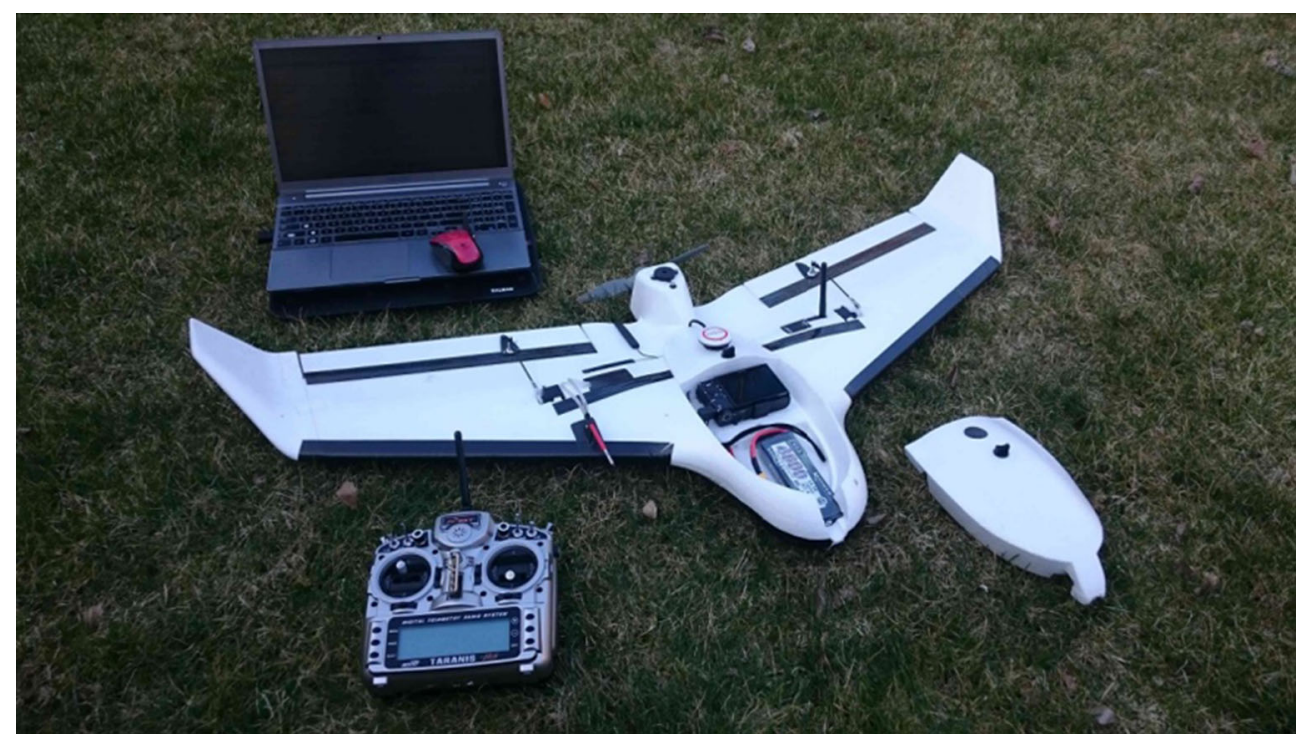

Figure 3

UAV system fitted with Sony RX100 camera

possible to operate a drone in four or more different flight modes: manual, assisted (FBWA—fly by wire alfa), full automatic (AUTO), and auto return to launch (RTL). Telemetry data are based on two $433-\mathrm{MHz}$ radios. The radio link module is connected directly to the flight computer (the Pixhawk flight controller). The fully charged lithium polymer (LiPO) battery $4600 \mathrm{mAh}$ provides a maximum flight time of $45 \mathrm{~min}$. In addition, the built-in safety features in the flight computer manage potentially dangerous situations: UAV can land manually or automatically when the battery is running low. Our fixed-wing prototype with $1180 \mathrm{~mm}$ wingspan can lift a Sony RX100 20MP camera (weighing $300 \mathrm{~g}$ with Seagull controller). The total weight of the UAV system is $1.35 \mathrm{~kg}$, including the battery and camera. Our UAV flight wing tolerates wind speed of up to $15 \mathrm{~m} / \mathrm{s}$ (a threshold that was never exceeded during data collection). The fixed-wing system requires a relatively small, clear take-off and landing area. To launch the flying wing a bungee system is obligatory. This solution provides high reliability of each take-off. A belly landing can be done in the auto, assisted or manual mode. An open source software named Mission Planner (GCS) is responsible for planning and operating the photogrammetry missions, setting up the drone and calibrations.
To acquire spatial resolution photographs during the Lake Suskie experimental measurements, a fixedwing UAS was assembled as follows (Fig. 3).

\subsection{Data Acquisition/Image Acquisition}

Our autonomous fixed-wing system can operate and take photographs automatically according to a flight plan (prepared in Mission Planner software). The drone is operational for approximately $45 \mathrm{~min}$ on a single battery. A Sony RX100 II camera with 20 effective megapixels was used to collect the photographs. The photo capture rate was controlled by the flight system control board, which was programmed to emit a trigger pulse at a desired frequency. The shutter of the camera was triggered by the Seagull steering controller, which was connected to the UAV control system. The stable flight of the UAV increases image quality and precision, while wind reduces it. The UAV was manually launched from a flat area near the lake. Manual control during the flight negatively affects image quality and resolution, especially in windy conditions. That is why images were acquired at a fixed height, under automatic flight control, while manual control was used for landing. Before each stage/flight 

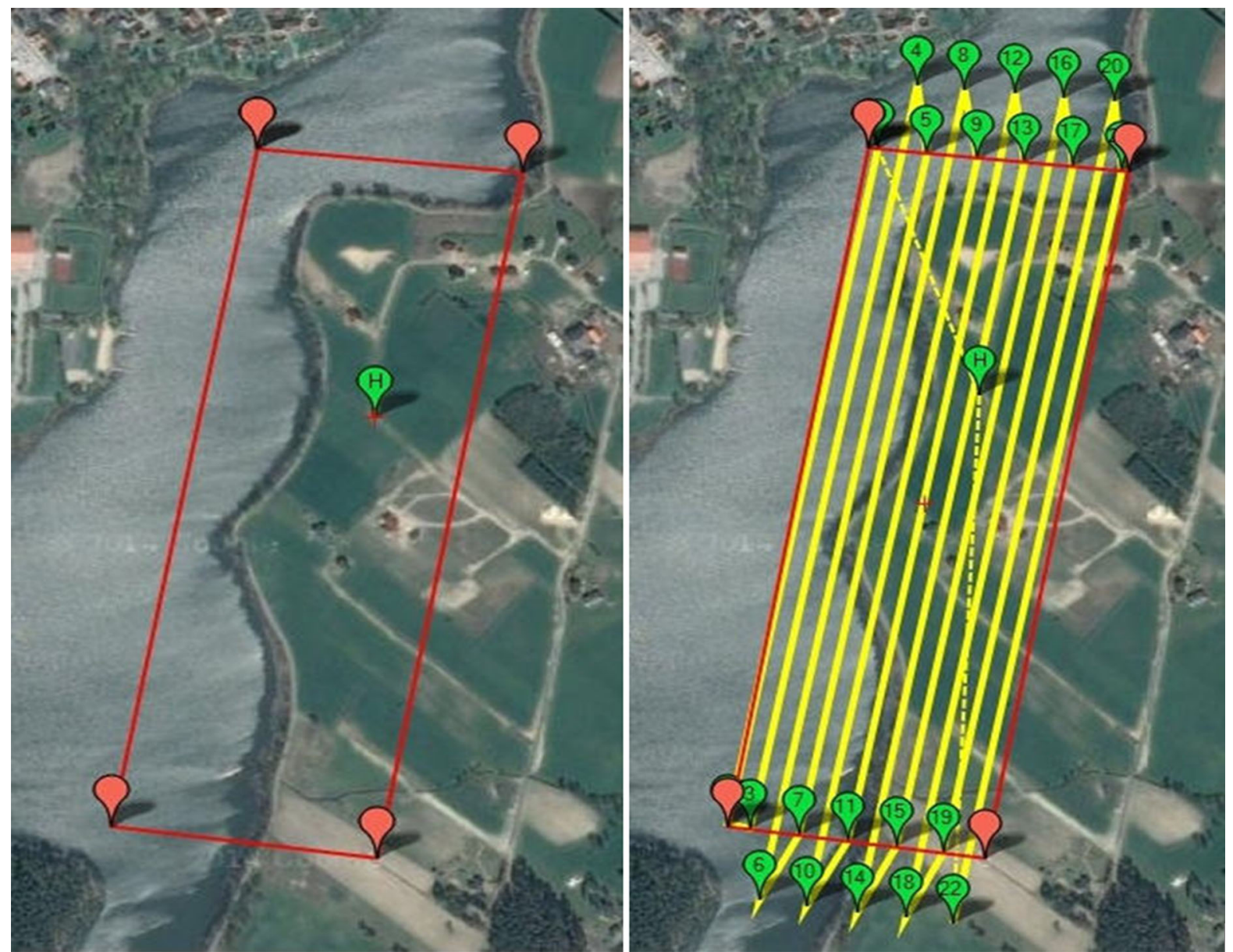

Figure 4

Investigated area (on the left). A flight path across the study area (on the right)

of the project, the front-lap image overlap was calculated to be $70 \%$, with a side-lap image overlap of $50 \%$, for a setting of one photograph per second.

The Lake Suskie is largely surrounded by forest or by single high trees. That is why flight altitudes ranged from 100 to $160 \mathrm{~m}$, depending on the covered area and the height of surrounding trees. During experimental measurements the ground control system was used to set flight parameters and to monitor the flight status. A remote control unit (RC) was used to operate the tailless fixed-wing platform manually in case of emergency.

Before the mission the flight plan was designed. The whole measurement area of Lake Suskie was divided into four parts. One of the tested areas presented in the research is shown in Fig. 4. This experimental flight area has 33 ha (including water) and covers $1600 \mathrm{~m}$ of shoreline. The take-off and landing site, marked as $\mathrm{H}$ in Fig. 4, was away from the edge of the lake. Because of high trees, hilly terrain and nearby construction works operating the UAV was neither easy nor comfortable.

\subsection{GNSS Survey, GCPs Determination}

To convert the image coordinates into geographical coordinates, ground control points (GCP) for the area of interest are required. Eight GPCs were used on the most interesting middle-east part of the lake described in the research (one flight from four covering the whole lake, Figs. 4, 5). 


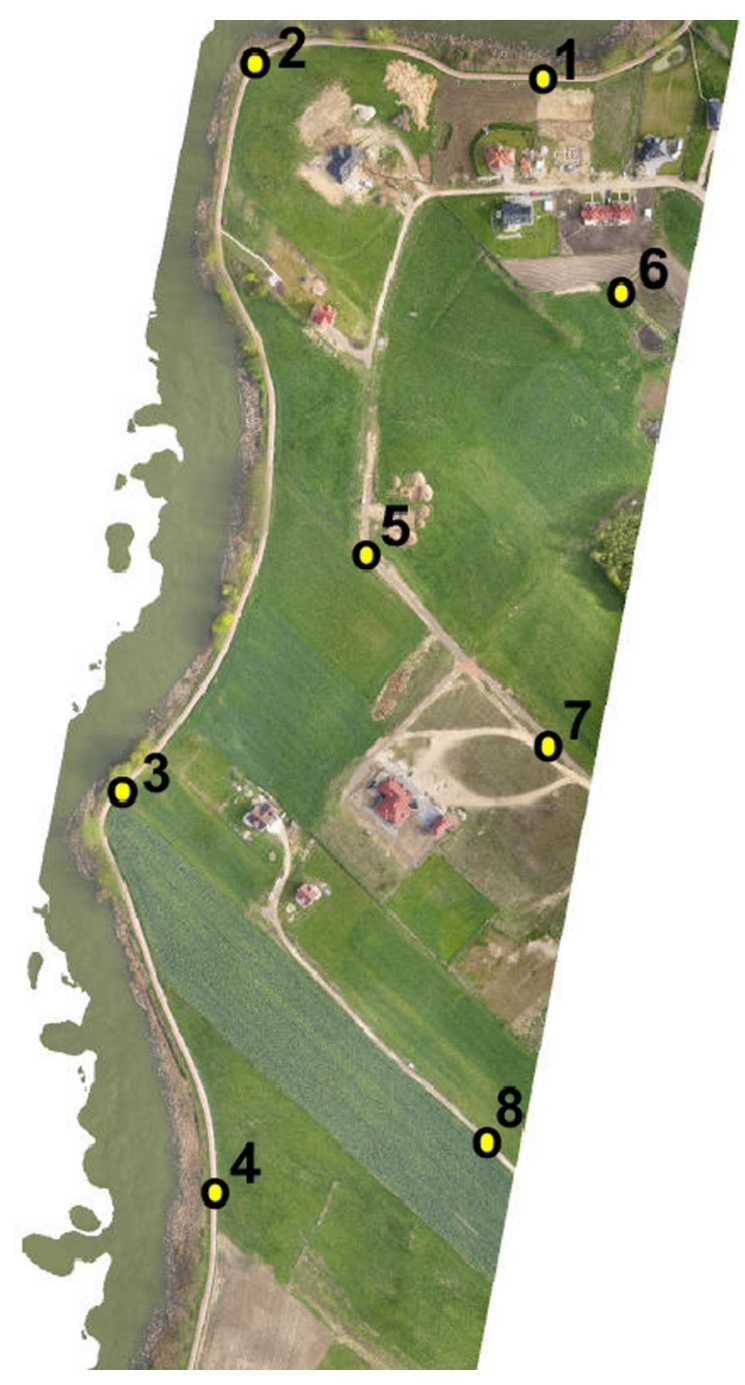

Figure 5

Ground control points location

The scale, resolution and precision of ground control points are the major factors affecting UAV image quality (Niethammer et al. 2012). GCPs were determined using GNSS Topcon HiperPro geodetic receivers. The raw GNSS/static/data were used for GCPs coordinates calculations. Static sessions were completed based on the four Ground-Based Augmentation System (GBAS) permanent reference stations ASG-EUPOS (Active Geodetic NetworkEUPOS): ELBL, GRUD, ILAW, STRG. The BLH WGS'84 horizontal geodetic coordinates were transformed into projected coordinates (ETRS 1989 Poland CS 2000 Zone 7). Vertical measurements were reduced to Kronsztad' 86 (vertical map datum in Poland-normal heights above sea level). The RMS error of GCP measurements was less than $10 \mathrm{~mm}$ horizontally and 15 vertically. The distribution of GCPs across the region of one stage of all flights, used for the georectification procedure, is shown as yellow dots in Fig. 5.

\subsection{Coastline Extraction and Comparison}

To evaluate a possible impact of data acquisition on the coarse line location, all existing materials have been analyzed and prepared for further work. The following data were discovered and acquired from the succeeding sources:

- Historical bathymetric plan from Inland Fisheries Institute in Olsztyn,

- Orthophoto from a Polish geoportal (http://www. geoportal.gov.pl), topographic and cadastral maps from government and regional offices,

- RTK surveys from on-site measurement campaign,

- UAV orthomosaic from on-site UAV surveys.

All the data were collected, analyzed and processed using distinctive techniques. The bathymetric plan provided by the Inland Fisheries Institute in Olsztyn in 1963 had been prepared on the basis of old conventional surveys. The old plan was first converted into a digital format and next digitized for further work. The feature classes representing course line were extracted from adjusted historical bathymetric data.

The classical manned aerial photo was acquired as an image from web map service (WMS) from a Polish geoportal. The topographic maps and cadastral data were obtained as vector layers in ESRI shape formats. They were transformed into common database and used as supported layers for aerial maps. The coarse line was digitized and saved as polyline layers.

The direct RTK/GNNS shoreline measurements were made with Trimble R8 geodetic RTK/GNSS receiver used for collecting float/fixed field data based on the single GBAS ASG-EUPOS reference station in Iława (ILAW). During the RTK a survey of 608 fixed/float points was collected. Unfortunately, as many as 228 points were measured by the float 
solution because of the trees and the difficult satellite situation. That is why the inventory of the coastline was completed using the developed unmanned aerial system.

The typical workflow was used for UAV image processing. It was based on the SfM method used in the Agisoft PhotoScan software. The processing chain consisted of the following steps: image matching, georeferencing, digital elevation model creation, orthomosaics, point cloud generation and texture model creation.

All steps were performed with ESRI ArcMap, version 10.4.1. All of the GIS datasets were created in the Polish projected "ETRS 1989 Poland CS 2000 Zone 7" coordinate system.

\section{Results}

The proposed methodology for acquiring reliable coastline and bathymetric information was implemented during Lake Suskie project. After performing comprehensive GNSS, hydroacoustic and aerial measurements on the reservoir, the authors have compiled a new shoreline and up-to-date bathymetric and morphometric data.

\subsection{Elaboration of Lake Suskie Boundaries}

The collected data were processed and analyzed using ESRI ArcGIS version 10.4.1 with the 3D Analyst/Spatial Analyst extension. The data were firstly imported into common ESRI geodatabase structure and processed sequentially. As a result four different shorelines were prepared. The visualization of the first three (historical, orthophoto and RTK) are presented in Fig. 7.

The UAV data require an additional task. In the presented part of the area 310 photographs were captured on the average $156 \mathrm{~m}$ flying altitude, encompassing coverage area of 34,53 ha. Figure 6 presents orthophotos and the DEM of the lake shoreline and the adjacent natural topography created during image processing. On the basis of our UAV mission the resolution of elaborated orthomosaics was at the level of 1-6 cm per pixel. These highresolution UAV images were next used to determine the lake borders. The on-screen digitization method was next used for shoreline extraction.

The calculated parameters of Lake Suskie are shown in Table 2. According to the UAV measurements conducted in 2015 the total area of the lake is 62.00 ha and the shoreline length is $5790 \mathrm{~m}$. The calculated area is similar to the area obtained from satellite images and RTK surveys. The shoreline length differs by 81 and $33 \mathrm{~m}$, respectively. According to the historical bathymetric plan the UAV area was reduced from 62.70 to 62.00 hectares. However, the shoreline increased from 5600 to $5790 \mathrm{~m}$.

Figure 7 presents comparisons of coastline extraction methods. The top left-the historical morphometric plans from IRS, lower-the orthophotomap from Head Office of Land Surveying and Cartography in Warsaw, the bottom left-RTK survey on the topographic map, on the right, the comparison of coastlines (historical, orthophoto, RTK, UAV).

\subsection{Lake Suskie DEM Generation and Morphometry Calculation}

After conducting all the stages of field experimental measurements on Lake Suskie, the current coastline with border of reeds, 3D bathymetric model and morphometric parameters were elaborated. The raw data from hydroacoustic sounding were processed and bathymetric points were converted into an ESRI multipoint feature class. The inventory of the coastline included historical data and Web Map Service (WMS) analysis, aerial remote sensing data from UAV and RTK/GNSS direct measurements. Figure 8 presents the northern part of the lake, including the following layers: isobaths, the coastline shape with measured points, the vegetation area. The red line shows the old coastline extracted from archival bathymetric plan.

The quality of the DEM is basically a function of the accuracy of individual survey points, field survey strategy and the method of interpolation (Heritage et al. 2009). The most popular ways to create DEM models are the regular grid surface (Grid) and triangulated irregular network (TIN) (El-Sheimy et al. 2005). The Lake Suskie DEM was generated with the use of ESRI ArcGIS 10.4.1 (Fig. 9). 

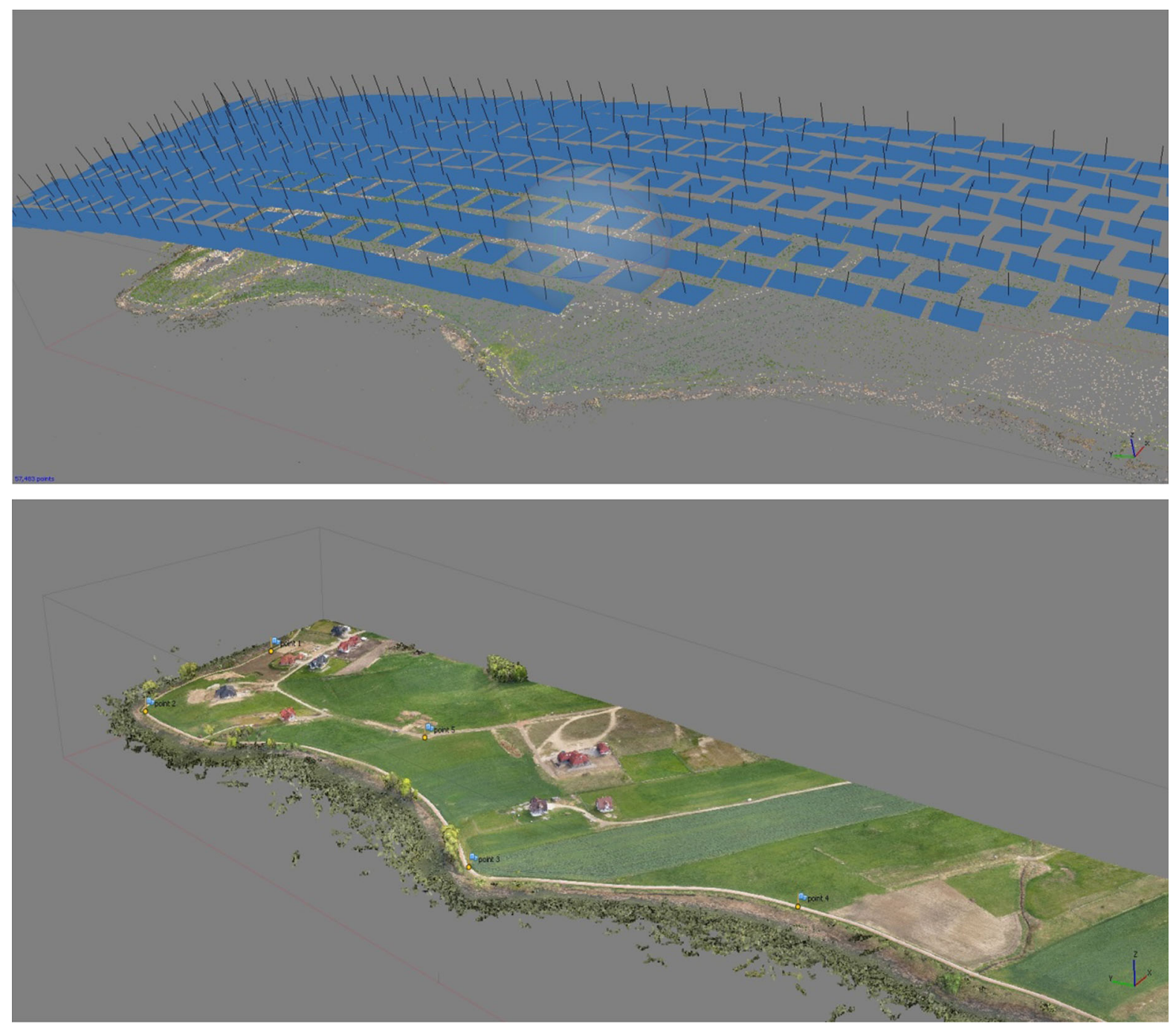

Figure 6

Study area orthophotos and DEM created in the Agisoft PhotoScan

Table 2

Area of the lake and shoreline length

\begin{tabular}{lllll}
\multicolumn{5}{c}{ Area of the lake and shoreline length } \\
\hline Method & $\begin{array}{l}\text { Bathymetric } \\
\text { plans }\end{array}$ & Orthophoto & RTK & UAV \\
& 1967 & 2014 & 2014 & 2015 \\
\hline Date & - & 0.50 & - & 0.06 \\
Resolution (m) & 62.70 & 61.99 & 61.99 & 62.00 \\
$\begin{array}{l}\text { Area (ha) } \\
\text { Shoreline }\end{array}$ & 5600 & 5709 & 5823 & 5790 \\
\multicolumn{1}{c}{ length (m) } & & & & \\
\hline
\end{tabular}

Bathymetric parameters such as volumetric and area calculations were derived using the TIN model. Contours, depth ranges, and the shaded relief map were derived from a DEM grid. The TIN surface was created using the collected bathymetric data points and the lake boundary inputs. The TIN consists of connected data points that form a network of triangles representing the bottom surface of the lake. This grid was created using the ArcMap Topo to Raster Tool and had a spatial resolution of $5 \mathrm{~m}$. Then the contours were generated and converted to polygon feature classes. They were attributed to show $0.5-\mathrm{m}$ depth ranges across the lake. At the end, the contour lines were edited to improve accuracy and to smooth the lines. 

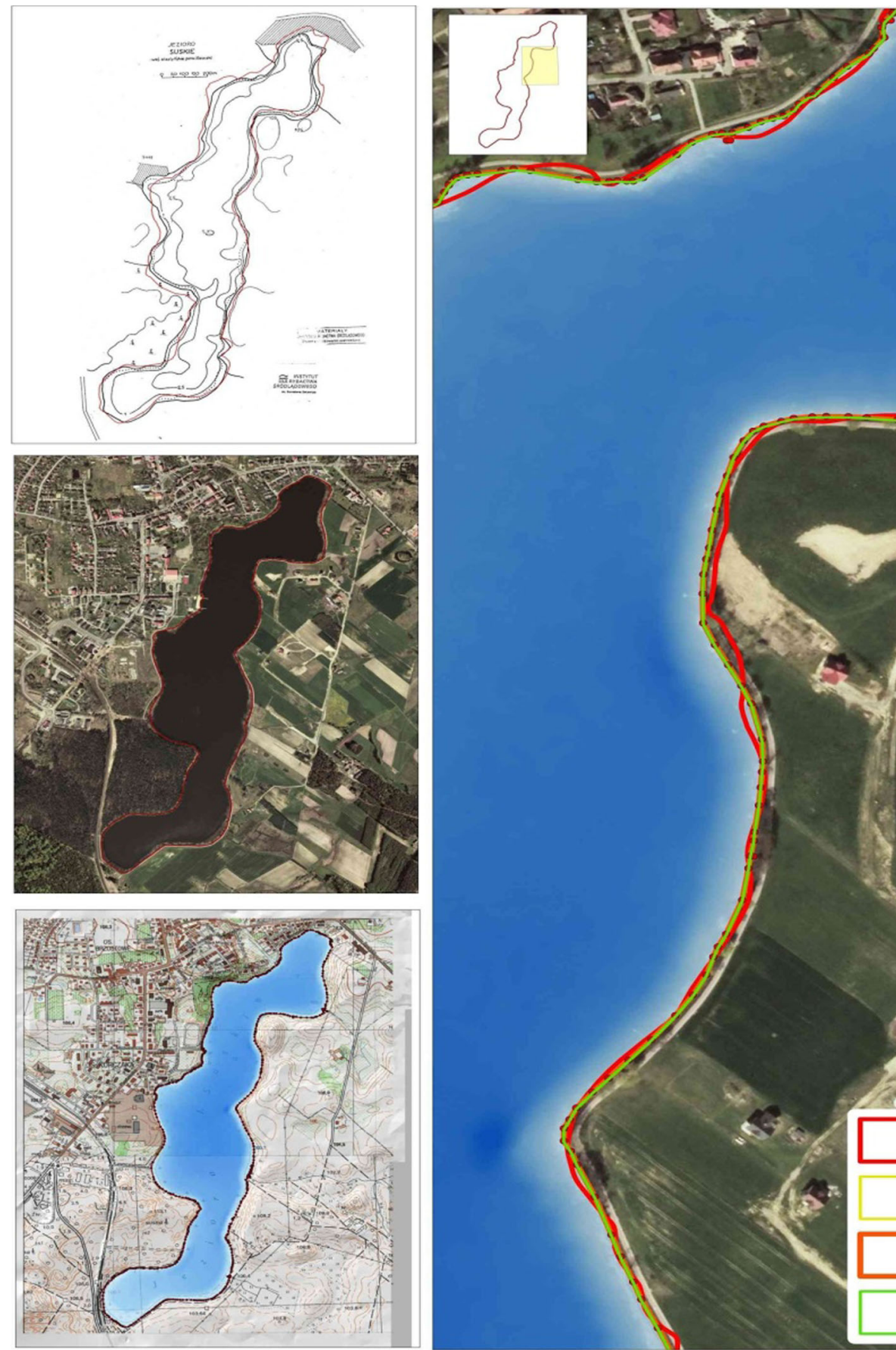


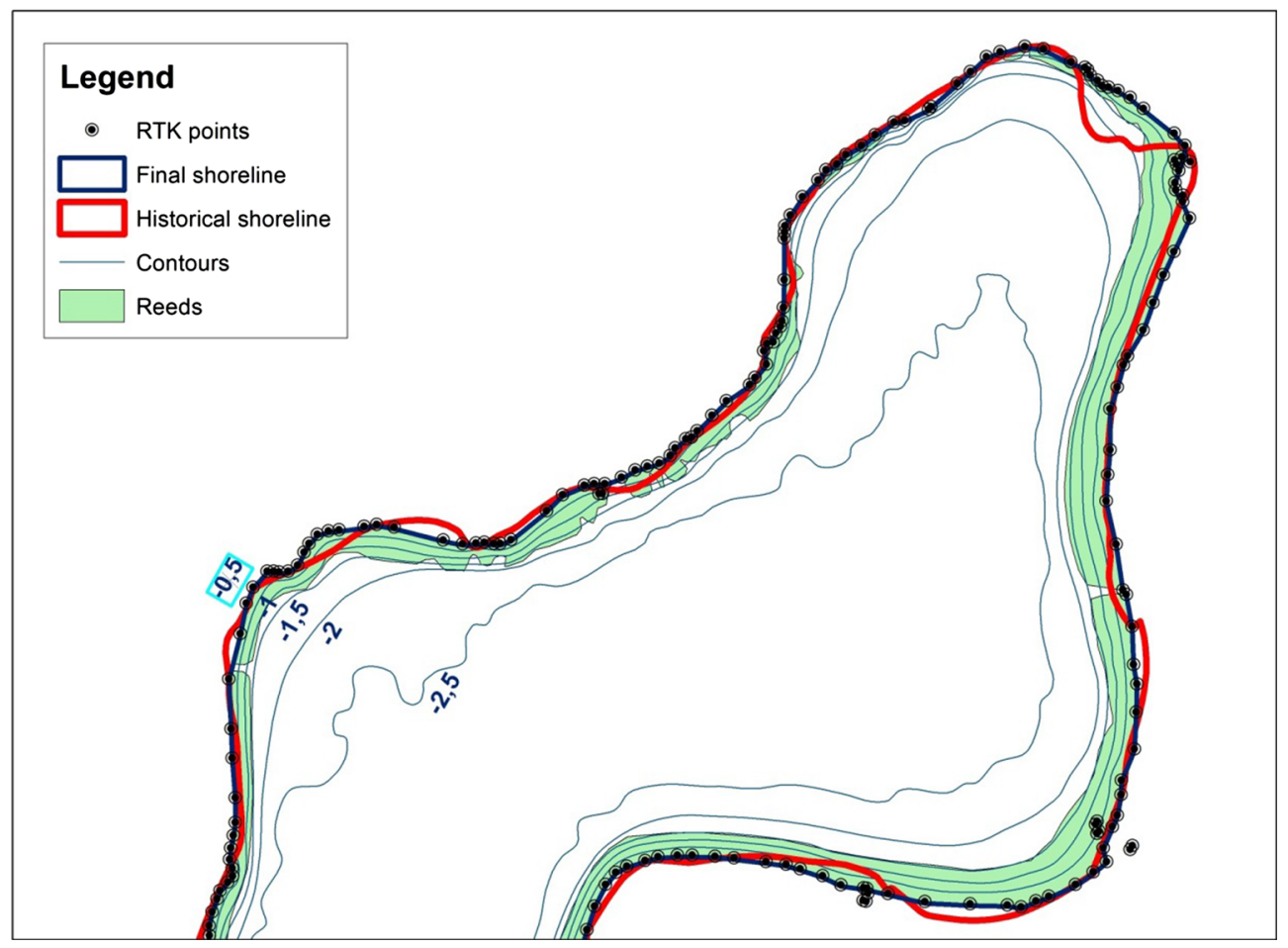

Figure 8

Measured points spatial distribution
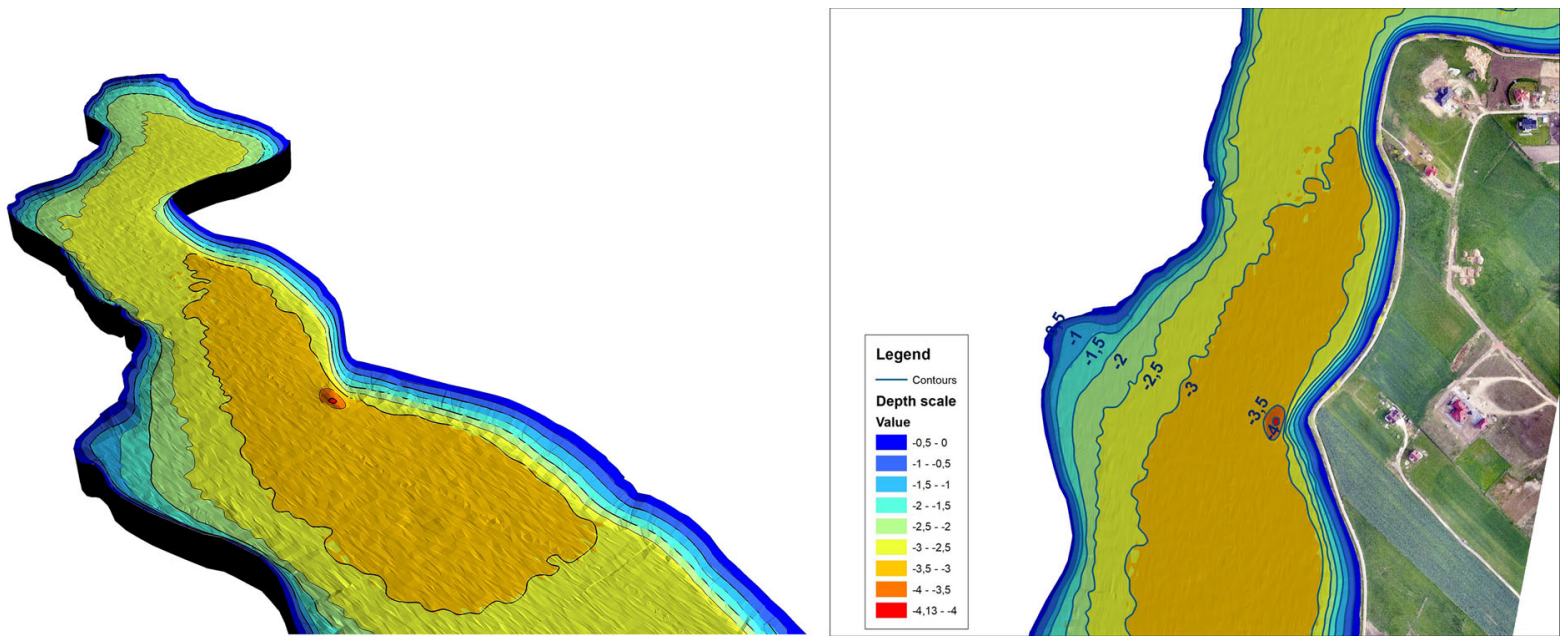

Figure 9

DEM of Lake Suskie and adjacent area

were calculated based on the methods and definitions described by Hutchinson, Wetzel, Choinski and Ławniczak (Choiński 2007; Hutchinson 1957; Wetzel 2001). The new Lake Suskie morphometry parameters on the basis of the last bathymetric, GNSS and
UAV measurements were calculated for the entire lake. The following morphometric parameters describing Lake Suskie were elaborated: max. lake length (m), max. and mean width (m), area (ha), shoreline length $(\mathrm{m})$, volume (m3), max. and mean 
Table 3

New morphometric parameters of Lake Suskie

\begin{tabular}{|c|c|c|}
\hline \multirow[b]{2}{*}{ Year } & \multicolumn{2}{|l|}{ Lake Suskie } \\
\hline & 1963 & 2015 \\
\hline Source & $\begin{array}{l}\text { Inland Fisheries Institute } \\
\text { in Olsztyn }\end{array}$ & $\begin{array}{l}\text { Popielarczyk, } \\
\text { Templin }\end{array}$ \\
\hline $\begin{array}{l}\text { Maximum lake length } \\
\quad\left(L_{\max }\right)(\mathrm{m})\end{array}$ & 2300.0 & 2251.9 \\
\hline $\begin{array}{l}\text { Maximum width } \\
\left(B_{\max }\right)(\mathrm{m})\end{array}$ & 475 & 449 \\
\hline Mean width $\left(B_{\min }\right)(\mathrm{m})$ & 272 & 275 \\
\hline Area (ha) & 62.7 & 62.0 \\
\hline Shoreline length (m) & 5600 & 5790 \\
\hline $\begin{array}{l}\text { Shore Development } \\
\text { Index } L_{\mathrm{dl}}\end{array}$ & 2.00 & 2.05 \\
\hline Volume $\left(\mathrm{m}^{3}\right)$ & $1,491,4000$ & $1,377,086$ \\
\hline $\begin{array}{l}\text { Maximum depth } \\
\left(D_{\max }\right)(\mathrm{m})\end{array}$ & 5.3 & 4.1 \\
\hline Mean depth $\left(D_{\min }\right)(\mathrm{m})$ & 2.4 & 2.2 \\
\hline Relative depth $\left(Z_{\mathrm{r}}\right)(\mathrm{m})$ & 0.0067 & 0.0052 \\
\hline
\end{tabular}

depth (m). Actual morphometry parameters are shown in Table 3.

It is important for these results to be considered in the future management of the shallow lake. Local authorities intended to use the new elaborated bathymetry and morphometry for the Lake Suskie reclamation project.

\section{Discussion}

Each of the presented methods of shorelines extraction is encumbered with errors, limiting its further use. The historical bathymetric plans, due to the paper form and lack of geodetic references, can only be used as information on the historical course of the coastline and contour lines to build the digital elevation model of the bottom. It can be then used for the analysis of spatio-temporal changes of the water reservoirs.

Photogrammetric data are a very good source to analyze the coastlines. However, the acquisition of classical manned aerial photos is still a very expensive and time-consuming process. The measurements are usually performed periodically. The orthophotomap used in the project is characterized by following parameters: the date of the picture taken for orthophoto-2014, pixel size $0.5 \mathrm{~m}$, RGB color. Due to the date, relatively low resolution (pixel size) and hard observation conditions on the shore, this method provides unreliable water environment information. The necessary geodata should be collected by direct measurements. RTK/GNSS measurements conducted under difficult satellite observation conditions have shown serious limitations during shoreline inventory. Nearly one-third of the measurements were characterized by a lack of a fixed solution. During the RTK measurements of the coastline or adjacent areas there are frequent problems with satellite signal loss or multipath effect. This is related to the fact that the banks of inland water reservoirs are often forested, or overgrown with single trees and brushes. This makes it much more difficult to perform GNSS geodetic measurements and sometimes even makes it impossible. Figure 10 shows some examples of the float RTK solutions in the immediate vicinity of the trees (Lake Suskie), even though the measurements were performed in early spring.

\subsection{Accuracy Analysis}

The inventory of the coastline and reed should be performed for further lake morphometry elaboration. So far, classical geodetic techniques or RTK/GNSS have traditionally been used. They are, however, time-consuming, and in some cases even impossible. Therefore, the authors decided to use UAV remote sensing for shoreline mapping. To check the coastline accuracy on the UAV-based orthophotomap, an accuracy analysis was performed on a fragment of the eastern part of the lake. The Trimble R8 geodetic RTK/GNSS receiver was used for collecting float/fixed field data based on the single GBAS ASGEUPOS reference station in Iława (ILAW). To analyze the horizontal and vertical accuracy of the coordinates of terrain details as determined from the UAV, a fragment of a concrete bicycle path around the lake was used as a reference. At the same time the comparison of the coastline and reed line was performed. Figure 11 presents horizontal and vertical coordinate differences.

The horizontal differences of the coordinates range from -0.033 to $0.020 \mathrm{~m}$. The mean value is $-0.007 \mathrm{~m}$. The results of the vertical surveys show 


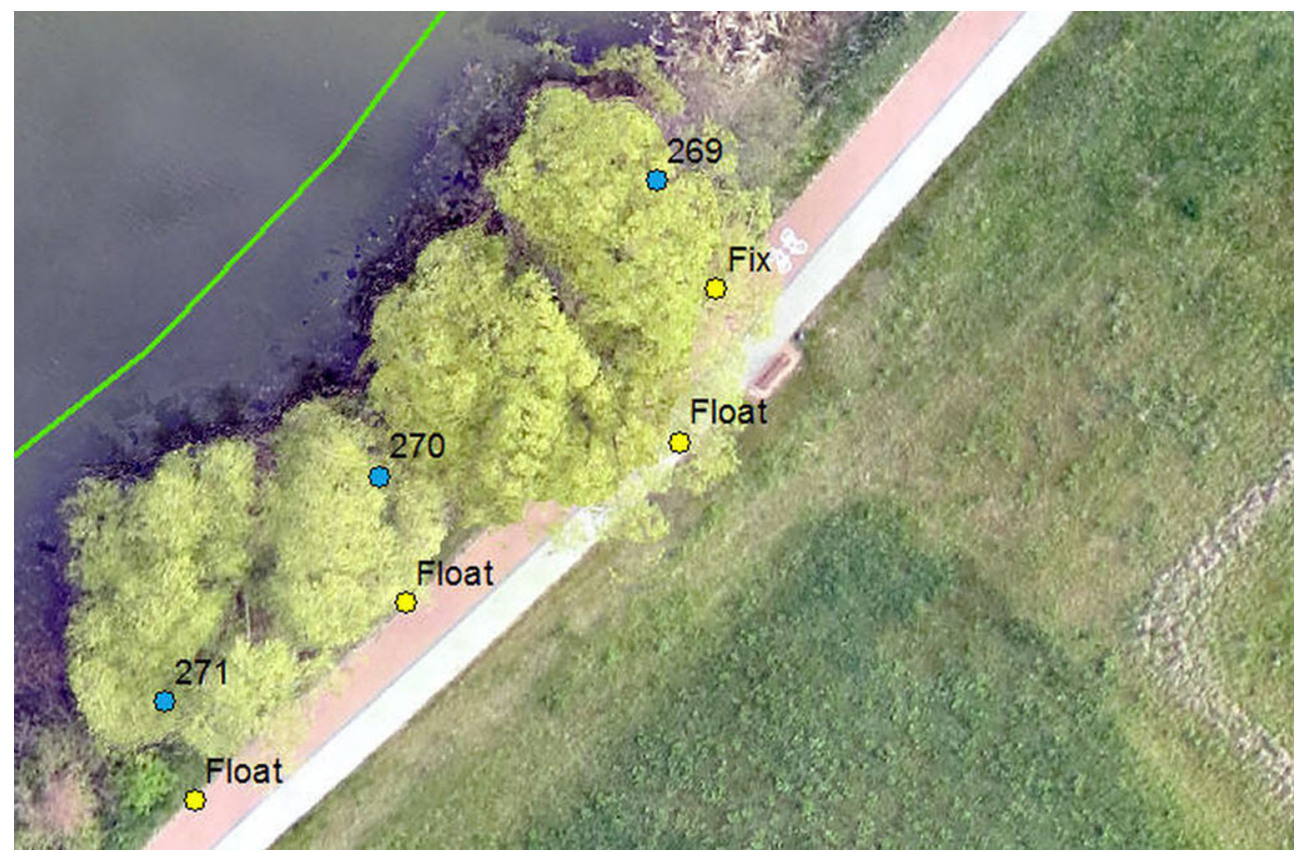

Figure 10

Float RTK/GNSS measurements problem

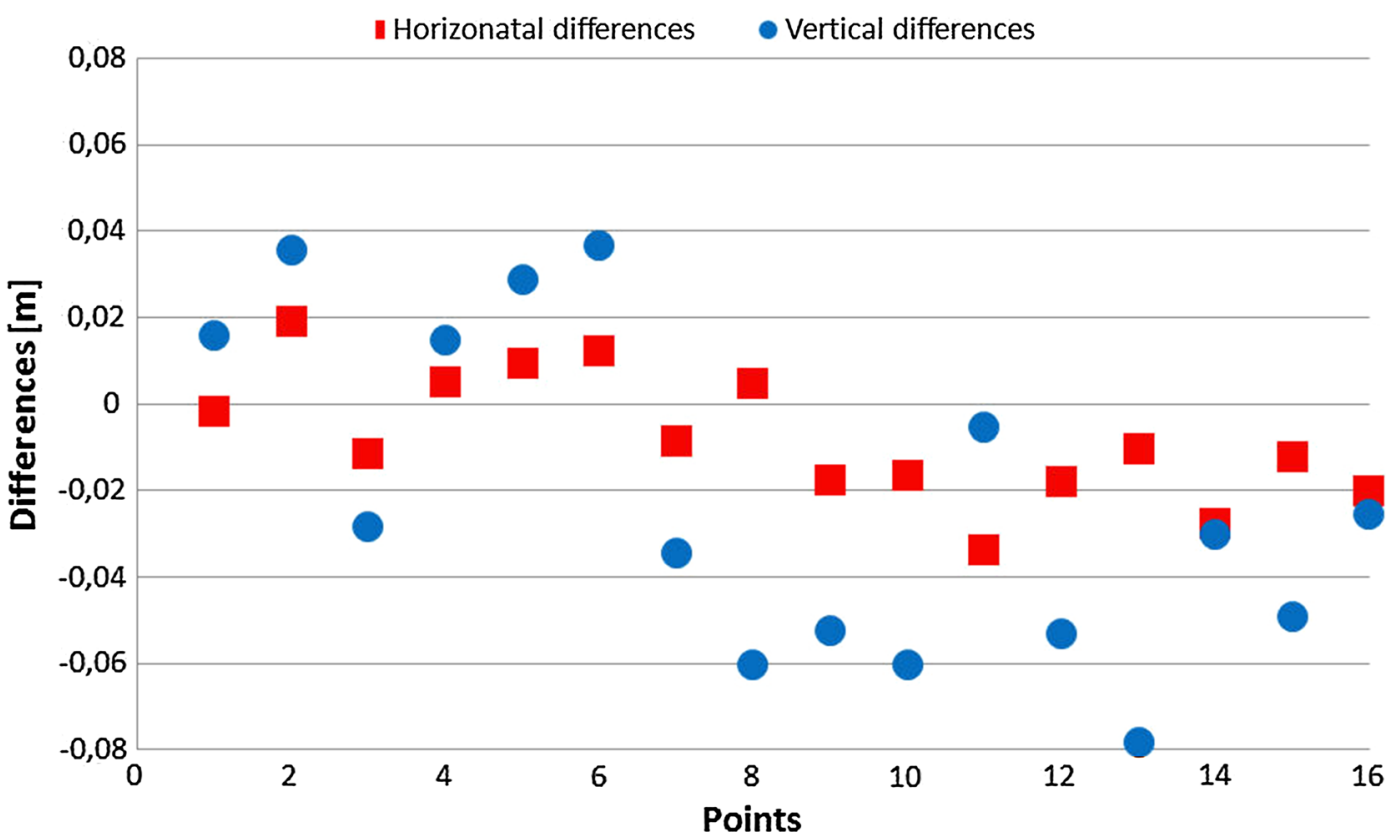

Figure 11

Accuracy of RTK/GNSS-UAV points analysis

that the differences between RTK and UAV heights range from -0.078 to $0.037 \mathrm{~m}$. The mean value of the vertical difference is $-0.021 \mathrm{~m}$. This analysis confirms that the UAV technique can be successfully used for determining the position and height of the terrain points with an accuracy of a few centimeters. 


\subsection{Morphometry Analysis}

In the presented research the authors describe geodetic, bathymetric and aerial measurements conducted on a small, urban lake, Lake Suskie, the final product of which is the development of a bathymetric map and morphometric parameters. The new integrated surveys show that the max depth of the lake is not $5.3 \mathrm{~m}$ (according to archival data from the Inland Fisheries Institute) but $4.1 \mathrm{~m}$ (Pawłowski 2014). The analysis of 1963 and 2013 survey suggests that over 50 years the surface area of Suskie Lake has changed from 62.7 to 62.0 ha and the lake volume has decreased from $1,491,400$ to $1,377,086 \mathrm{~m}^{3}$. Moreover, meaningful changes in the shoreline were observed, which had a significant impact on the morphometric data of the lake. The coastline length has increased from 5600 to $5790 \mathrm{~m}$. During the measurements and the raw data elaboration process all bathymetric data were referenced to the common, reference water level.

By analyzing archival maps, aerial photo and satellite images, it is evident on the archival bathymetric plan that the shape of the coastline is significantly different from archival geodesic materials (in some places the differences are several dozen meters). It can be concluded that the incompatibility of the coastline is due to the imperfection of the measurement methods used in the bathymetric process. The contemporary coastline only slightly differs from archival geodetic materials. On the other hand, it differs significantly from the old bathymetric plan.

As far as bathymetry is concerned, it is difficult to draw clear conclusions as to why the archival depth map differs from the current one. The old bathymetric plan indicates a maximum depth of $5.3 \mathrm{~m}$ centrally in the middle of the lake. Contemporary, professional hydroacoustic measurements have defined a maximum depth of $4.1 \mathrm{~m}$ in another part, $200 \mathrm{~m}$ northeast of the center of the lake. It should be emphasized that archival and current measurement results have been reduced to a common water level for analysis. The sonar echograms at two frequencies indicate a layer of loose organic sediment on the bottom of the entire lake, with a thickness of $20-40 \mathrm{~cm}$. Ultimately, it can be concluded that differences in bathymetry and morphometric parameters are partly due to the imperfection of old analog measurement methods (particularly positioning) and significant eutrophication, which happens in many lakes under anthropo pressure. Accuracy and reliability of raw measurement data significantly affect the bathymetry and can be a very important issue in the interpretation of the water environmental change. The presented results show that the bathymetric data and morphometric parameters of lakes, used for morphometric study and research in hydrobiology, limnology, fisheries and other environmental research, are highly dependent on the research methodology used, precise water level determination, reliable shoreline investigation, collected raw data, bathymetric and aerial maps elaboration processes.

\subsection{Self-Built Fixed-Wing UAVs Future}

Recent advances in drone technology, combined with low-weight sensors, provide a new method for mapping water areas at high resolution. A low-cost UAV system with a camera can quickly collect photographs of the shallow lake shoreline and inaccessible adjacent areas. Without human risk, it provides geoinformation with high accuracy. Therefore, the proposed and implemented low-cost UAV system can support the classical geodetic total station and RTK/GNSS technologies but, above all, it significantly supports the bathymetric measurements of inland, shallow lakes.

Nowadays, there are many complex aerial mapping systems on the geodetic market. The main advantages of a self-built fixed-wing platform over the commercial ones are undoubtedly a low price and a possibility of easy repair or improvement. Other advantages include own configuration of the UAS, a possibility to adapt various kinds of data collection and navigation sensors, and open source firmware being developed faster than commercial. Additionally, a mission planning tool is much more advanced. The main inconveniences of the self-built UAS are: much more time needed for building and testing and the lack of guaranty and technical support. The proposed fixed-wing UAS does not really compete with traditional photogrammetric flights, but offers interesting options for small water areas, where the cost of traditional flights is simply too high. 
Our study confirms the relevance of UAVs platform in water applications and is consistent with previous results (Čermáková et al. 2016; Venturi et al. 2016; Yucel and Turan 2016). The solutions presented in those articles are based on off-the-shelf multi-rotor platforms. Their methodology and results validate the usefulness of UAVs platform for shoreline extraction and changes detection on small water reservoirs. These studies are preliminary and authors declare further study of UAVs, especially regarding the possibility to utilize other sensors on the platform (for example, for water pollution identification, chemical analyses, water samples). There are many platforms developed by academic institutions (Cai et al. 2014), but usually access to them is limited. There are some examples in literature describing the process of building UAVs platform (Anweiler and Piwowarski 2017; Sørensen et al. 2017). They are based on open standards and components but are usually constructed as a multi-rotor type of UAV. Our fixed-wing solution is similar, but offers a great opportunity to implement a new GNSS/IMU components and additional sensors. Both active and passive sensors can be used to improve the process of data acquisition (Dietrich 2017). The promising results suggest a further need for testing UAV platform to raise capacities and extend their applications.

\section{Conclusions}

The main objective of the present work was to describe an application of a low-cost tailless fixedwing UAV for inland lake shoreline and adjacent area investigation. The proposed methodology uses an unmanned aerial system constructed and implemented specifically for small inland reservoirs (like Lake Suskie). A fixed-wing UAS, developed and implemented by the authors, can provide an excellent tool for accurate surveys of a shallow lake shoreline. It also provides valuable geoinformation data definitely faster than the traditional total station/RTK methods.

The constructed tailless UAV was made of widely available parts and open-source software. Images collected during the research were recorded using the Sony RX100 camera and elaborated with open source software. Precisely determined GCPs should be used to increase the accuracy of the final results. Static or RTK/GNSS methods need to be utilized for control points measured with $1 \mathrm{~cm}$ accuracy. The proposed solution improves the efficiency and makes it possible to get reliable results and accuracy comparable to the conventional techniques. Depending on the survey area and the UAV type, drones may offer a more economic survey platform than a crewed aircraft. They can also fly more slowly, at lower altitudes, allowing for safe use of high-resolution sensors. Just as aerial and satellite sensing have transformed scientific observations, allowing the resolution of largescale physical processes, the pervasive use of drones is set to revolutionize geophysical sciences through the rapid and refined measurement of small-to-medium scale phenomena (Famiglietti et al. 2015; Tauro et al. 2016).

The proposed methodology shows that even a low-cost fixed-wing UAV can provide an excellent tool for accurately surveying a shallow lake shoreline and generate reliable geoinformation data collected faster than when traditional geodetic methods are employed. The presented study is only the first step to construct a universal, multifunctional platform for both passive and active sensors to acquire complex information about water environment.

Measurements made with the use of UAV methodology and orthomosaic seem to be one of the best options for water environment investigation. High-resolution (pixel at the level of centimeters) and up-to-date data provide reliable information on the coastline in a relatively short period of time. The proposed and implemented UAS platform can be easily extended by additional passive or active sensors. The raw data can be captured in a wider range of electromagnetic spectrum or by active sensors like laser scanners.

Open Access This article is distributed under the terms of the Creative Commons Attribution 4.0 International License (http://creativecommons.org/licenses/by/4.0/), which permits unrestricted use, distribution, and reproduction in any medium, provided you give appropriate credit to the original author(s) and the source, provide a link to the Creative Commons license, and indicate if changes were made. 


\section{REFERENCES}

AgiSoft. (2010). AgiSoft PhotoScan professional edition. http:// www.agisoft.com. Accessed 27 Mar 2017.

Aguirre-Gómez, R., Salmerón-García, O., Gómez-Rodríguez, G., \& Peralta-Higuera, A. (2016). Use of unmanned aerial vehicles and remote sensors in urban lakes studies in Mexico. International Journal of Remote Sensing. https://doi.org/10.1080/ 01431161.2016.1264031.

Anderson, K., \& Gaston, K. J. (2013). Lightweight unmanned aerial vehicles will revolutionize spatial ecology. Frontiers in Ecology and the Environment, 11(3), 138-146. https://doi.org/10. 1890/120150.

Anweiler, S., \& Piwowarski, D. (2017). Multicopter platform prototype for environmental monitoring. Journal of Cleaner Production, 155, 204-211. https://doi.org/10.1016/j.jclepro. 2016.10.132.

Cai, G., Dias, J., \& Seneviratne, L. (2014). A survey of small-scale unmanned aerial vehicles: Recent advances and future development trends. Unmanned Systems, 2(2), 175-199. https://doi.org/ 10.1142/S2301385014300017.

Casella, E., Rovere, A., Pedroncini, A., Mucerino, L., Casella, M., Cusati, L. A., et al. (2014). Study of wave runup using numerical models and low-altitude aerial photogrammetry: A tool for coastal management. Estuarine Coastal and Shelf Science, 149, 160-167. https://doi.org/10.1016/j.ecss.2014.08.012.

Čermáková, I., Komárková, J., \& Sedlák, P. (2016). Using UAV to detect shoreline changes: Case study-pohranov pond, Czech Republic. In: International Archives of the Photogrammetry, Remote Sensing and Spatial Information Sciences-ISPRS Archives (Vol. 2016-Jan, pp. 803-808). https://doi.org/10.5194/ isprsarchives-XLI-B1-803-2016.

Choiński, A. (2006). Polish Lake catalogue. Poznań: Adam Mickiewicz University Publishing. (in Polish).

Choiński, A. (2007). Physical limnology of Poland. Poznań: Adam Mickiewicz University Publishing. (in Polish).

Colomina, I., \& Molina, P. (2014). Unmanned aerial systems for photogrammetry and remote sensing: A review. ISPRS Journal of Photogrammetry and Remote Sensing. https://doi.org/10.1016/ j.isprsjprs.2014.02.013.

d'Oleire-Oltmanns, S., Marzolff, I., Peter, K., \& Ries, J. (2012). Unmanned aerial vehicle (UAV) for monitoring soil erosion in Morocco. Remote Sensing, 4(12), 3390-3416. https://doi.org/10. 3390/rs4113390.

Dietrich, J. T. (2017). Bathymetric structure-from-motion: Extracting shallow stream bathymetry from multi-view stereo photogrammetry. Earth Surface Processes and Landforms, 42(2), 355-364. https://doi.org/10.1002/esp.4060.

El-Sheimy, N., Valeo, C., \& Habib, A. (2005). Digital terrain modeling: Acquisition, manipulation, and applications. Norwood: Artech House.

Everaerts, J. (2008). The use of unmanned aerial vehicles (UAVs) for remote sensing and mapping. The International Archives of the Photogrammetry Remote Sensing and Spatial Information Sciences, 37(2008), 1187-1192.

Famiglietti, J. S., Cazenave, A., Eicker, A., Reager, J. T., Rodell, M., \& Velicogna, I. (2015). Satellites provide the big picture. Science, 349(6249). http://science.sciencemag.org/content/349/ 6249/684.2. Accessed 21 Apr 2017.
Fonstad, M. A., \& Marcus, W. A. (2005). Remote sensing of stream depths with hydraulically assisted bathymetry (HAB) models. Geomorphology, 72(1), 320-339. https://doi.org/10.1016/ j.geomorph.2005.06.005.

Gonçalves, J. A., \& Henriques, R. (2015). UAV photogrammetry for topographic monitoring of coastal areas. ISPRS Journal of Photogrammetry and Remote Sensing, 104, 101-111. https://doi. org/10.1016/j.isprsjprs.2015.02.009.

Gülch, E. (2012). Photogrammetric evaluation of multi-temporal fixed wing UAV imagery. International Archives of the Photogrammetry Remote Sensing and Spatial Information Sciences, XXXVIII-1/(September), 265-270. https://doi.org/10.5194/ isprsarchives-XXXVIII-1-C22-265-2011.

Haala, N., Cramer, M., Weimer, F., \& Trittler, M. (2012). Performance test on UAV-based data collection. International Archives of the Photogrammetry Remote Sensing and Spatial Information Sciences, XXXVIII-1/, 7-12. https://doi.org/10.5194/ isprsarchives-XXXVIII-1-C22-7-2011.

Harvey, M. C., Rowland, J. V., \& Luketina, K. M. (2016). Drone with thermal infrared camera provides high resolution georeferenced imagery of the Waikite geothermal area, New Zealand. Journal of Volcanology and Geothermal Research, 325, 61-69. https://doi.org/10.1016/j.jvolgeores.2016.06.014.

Heine, I., Stüve, P., Kleinschmit, B., \& Itzerott, S. (2015). Reconstruction of lake level changes of groundwater-fed lakes in Northeastern Germany using rapideye time series. Water, 7(8), 4175-4199. https://doi.org/10.3390/w7084175.

Hengl, T., Reuter, H. I., \& Institute for Environment and Sustainability (European Commission, Joint Research Centre). (2009). Geomorphometry: Concepts software applications. Oxford: Elsevier.

Heritage, G. L., Milan, D. J., Large, A. R. G., \& Fuller, I. C. (2009). Influence of survey strategy and interpolation model on DEM quality. Geomorphology, 112(3-4), 334-344. https://doi. org/10.1016/j.geomorph.2009.06.024.

Huang, H., Long, J., Lin, H., Zhang, L., Yi, W., \& Lei, B. (2017). Unmanned aerial vehicle based remote sensing method for monitoring a steep mountainous slope in the Three Gorges Reservoir, China. Earth Science Informatics. https://doi.org/10. 1007/s12145-017-0291-9.

Hutchinson, G. E. (1957). A treatise on limnology. Part 1: Geography and physics of lakes. Limnology (Vol. 1). New York: Wiley.

Immerzeel, W. W., Kraaijenbrink, P. D. A., Shea, J. M., Shrestha, A. B., Pellicciotti, F., Bierkens, M. F. P., et al. (2014). Highresolution monitoring of Himalayan glacier dynamics using unmanned aerial vehicles. Remote Sensing of Environment, 150, 93-103. https://doi.org/10.1016/j.rse.2014.04.025.

Inland Fisheries Institute in Olsztyn. (1963). Bathymetric plan of Lake Suskie. Olsztyn.

Jancosek, M., \& Pajdla, T. (2011). Multi-view reconstruction preserving weakly-supported surfaces. In: CVPR 2011 (pp. 3121-3128). IEEE. https://doi.org/10.1109/CVPR.2011. 5995693.

Javernick, L., Brasington, J., \& Caruso, B. (2014). Modeling the topography of shallow braided rivers using structure-from-motion photogrammetry. Geomorphology, 213, 166-182. https://doi.org/10.1016/j.geomorph.2014.01.006.

Johnson, K., Nissen, E., Saripalli, S., Arrowsmith, J. R., McGarey, P., Scharer, K., et al. (2014). Rapid mapping of ultrafine fault 
zone topography with structure from motion. Geosphere, 10(5), 969-986. https://doi.org/10.1130/GES01017.1.

Kageyama, Y., Takahashi, J., Nishida, M., Kobori, B., \& Nagamoto, D. (2016). Analysis of water quality in Miharu dam reservoir, Japan, using UAV data. IEEJ Transactions on Electrical and Electronic Engineering, 11(S1), S183-S185. https://doi.org/10.1002/tee.22253.

Koparan, C., \& Koc, A. B. (2016). Unmanned Aerial Vehicle (UAV) assisted water sampling. In: 2016 ASABE international meeting (p. 1). American Society of Agricultural and Biological Engineers. https://doi.org/10.13031/aim.20162461157.

Liu, P., Chen, A. Y., Nan Huang, Y., Yu Han, J., Sung Lai, J., Chung Kang, S., et al. (2014). A review of rotorcraft unmanned aerial vehicle (UAV) developments and applications in civil engineering. Smart Structures and Systems, 13(6), 1065-1094. https://doi.org/10.12989/sss.2014.13.6.1065.

Łopata, M., Popielarczyk, D., Templin, T., Dunalska, J., Wiśniewski, G., Bigaj, I., et al. (2014). Spatial variability of nutrients $(\mathrm{N}, \mathrm{P})$ in a deep, temperate lake with a low trophic level supported by global navigation satellite systems, geographic information system and geostatistics. Water Science and Technology, 69(9), 1834-1845. https://doi.org/10.2166/wst.2014.084.

Lossow, K., Gawrońska, H., Łopata, M., \& Jaworska, B. (2004). Selection criteria for restoration method on Lake Suskie. Limnological Review, 4, 143-152.

Lucieer, A., de Jong, S. M., \& Turner, D. (2014a). Mapping landslide displacements using Structure from Motion (SfM) and image correlation of multi-temporal UAV photography. Progress in Physical Geography, 38(1), 97-116. https://doi.org/10.1177/ 0309133313515293.

Lucieer, A., Turner, D., King, D. H., \& Robinson, S. A. (2014b). Using an unmanned aerial vehicle (UAV) to capture micro-topography of Antarctic moss beds. International Journal of Applied Earth Observation and Geoinformation, 27, 53-62. https://doi.org/10.1016/j.jag.2013.05.011.

Mancini, F., Dubbini, M., Gattelli, M., Stecchi, F., Fabbri, S., \& Gabbianelli, G. (2013). Using unmanned aerial vehicles (UAV) for high-resolution reconstruction of topography: The structure from motion approach on coastal environments. Remote Sensing, 5(12), 6880-6898. https://doi.org/10.3390/rs5126880.

Marshall, D. M., Barnhart, R. K., Shappee, E., \& Most, M. T. (2016). Introduction to unmanned aircraft systems, 2nd edn. Boca Raton, FL, USA: CRC Press.

McEvoy, J. F., Hall, G. P., \& McDonald, P. G. (2016). Evaluation of unmanned aerial vehicle shape, flight path and camera type for waterfowl surveys: Disturbance effects and species recognition. PeerJ, 4, e1831. https://doi.org/10.7717/peerj.1831.

Meier, L., Tanskanen, P., Heng, L., Lee, G. H., Fraundorfer, F., \& Pollefeys, M. (2012). PIXHAWK: A micro aerial vehicle design for autonomous flight using onboard computer vision. $A u$ tonomous Robots, 33(1-2), 21-39. https://doi.org/10.1007/ s10514-012-9281-4.

Mori, Y., Takahashi, A., Mehlum, F., \& Watanuki, Y. (2002). An application of optimal diving models to diving behaviour of $\operatorname{Br}\{\ddot{u}\}$ nnich's guillemots. Animal Behaviour, 64(5), 739-745.

Nex, F., \& Remondino, F. (2014). UAV for 3D mapping applications: A review. Applied Geomatics, 6(1), 1-15. https://doi.org/ 10.1007/s12518-013-0120-x.

Niedzielski, T., Witek, M., \& Spallek, W. (2016). Observing river stages using unmanned aerial vehicles. Hydrology and Earth
System Sciences, 20(8), 3193-3205. https://doi.org/10.5194/hess20-3193-2016.

Niethammer, U., James, M. R., Rothmund, S., Travelletti, J., \& Joswig, M. (2012). UAV-based remote sensing of the SuperSauze landslide: Evaluation and results. Engineering Geology, 128, 2-11. https://doi.org/10.1016/j.enggeo.2011.03.012.

Papakonstantinou, A., Topouzelis, K., \& Pavlogeorgatos, G. (2016). Coastline zones identification and 3D coastal mapping using UAV spatial data. ISPRS International Journal of GeoInformation, 5(6), 75. https://doi.org/10.3390/ijgi5060075.

Pawłowski, B. (2014). Problems of reclamation of lakes with special emphasis on the Lake Suskie. Torun-Susz: Nicolaus Copernicus University in Toruń. (in Polish).

Popielarczyk, D., \& Templin, T. (2014). Application of integrated GNSS/hydroacoustic measurements and GIS geodatabase models for bottom analysis of Lake Hancza: The deepest inland reservoir in Poland. Pure and Applied Geophysics, 171(6), 997-1011. https://doi.org/10.1007/s00024-013-0683-9.

Popielarczyk, D., Templin, T., \& Łopata, M. (2015). Using the geodetic and hydroacoustic measurements to investigate the bathymetric and morphometric parameters of Lake Hancza (Poland). Open Geosciences. https://doi.org/10.1515/geo-20150067.

Ryan, J. C., Hubbard, A. L., Box, J. E., Todd, J., Christoffersen, P., Carr, J. R., et al. (2015). UAV photogrammetry and structure from motion to assess calving dynamics at Store Glacier, a large outlet draining the Greenland ice sheet. The Cryosphere, 9(1), 1-11. https://doi.org/10.5194/tc-9-1-2015.

Shervais, K. (2015). Structure from Motion Introductory Guide. https://www.unavco.org/education/resources/modules-andactivities/field-geodesy/module-materials/sfm-intro-guide.pdf. Accessed 18 Apr 2017.

Shintani, C., \& Fonstad, M. A. (2017). Comparing remote-sensing techniques collecting bathymetric data from a gravel-bed river. International Journal of Remote Sensing. https://doi.org/10.1080/ 01431161.2017.1280636.

Smith, M. W., Carrivick, J. L., \& Quincey, D. J. (2016). Structure from motion photogrammetry in physical geography. Progress in Physical Geography, 40(2), 247-275. https://doi.org/10.1177/ 0309133315615805.

Snavely, N., Seitz, S. M., \& Szeliski, R. (2008). Modeling the world from internet photo collections. International Journal of Computer Vision, 80(2), 189-210. https://doi.org/10.1007/ s11263-007-0107-3.

Sørensen, L., Jacobsen, L., \& Hansen, J. (2017). Low cost and flexible UAV deployment of sensors. Sensors, 17(1), 154. https://doi.org/10.3390/s17010154.

Szostak, M., Wezyk, P., \& Tompalski, P. (2014). Aerial orthophoto and airborne laser scanning as monitoring tools for land cover dynamics: A case study from the Milicz forest district (Poland). Pure and Applied Geophysics, 171(6), 857-866. https://doi.org/ 10.1007/s00024-013-0668-8.

Szulwic, J., Burdziakowski, P., Janowski, A., Przyborski, M., Tysiac, P., Wojtowicz, A., et al. (2015). Maritime laser scanning as the source for spatial data. Polish Maritime Research, 22(4), 9-14. https://doi.org/10.1515/pomr-2015-0064.

Tamminga, A. D., Eaton, B. C., \& Hugenholtz, C. H. (2015). UASbased remote sensing of fluvial change following an extreme flood event. Earth Surface Processes and Landforms, 40(11), 1464-1476. https://doi.org/10.1002/esp.3728. 
Tang, L., \& Shao, G. (2015). Drone remote sensing for forestry research and practices. Journal of Forestry Research, 26(4), 791-797. https://doi.org/10.1007/s11676-015-0088-y.

Tauro, F., Porfiri, M., \& Grimaldi, S. (2016). Surface flow measurements from drones. Journal of Hydrology, 540, 240-245. https://doi.org/10.1016/j.jhydrol.2016.06.012.

Toth, C., \& Jóźków, G. (2016). Remote sensing platforms and sensors: A survey. ISPRS Journal of Photogrammetry and Remote Sensing, 115, 22-36. https://doi.org/10.1016/j.isprsjprs. 2015.10.004.

Venturi, S., Di Francesco, S., Materazzi, F., \& Manciola, P. (2016). Unmanned aerial vehicles and Geographical Information System integrated analysis of vegetation in Trasimeno Lake, Italy. Lakes and Reservoirs Research and Management, 21(1), 5-19. https://doi.org/10.1111//re.12117.

Wallace, L., Lucieer, A., Watson, C., \& Turner, D. (2012). Development of a UAV-LiDAR system with application to forest inventory. Remote Sensing, 4(12), 1519-1543. https://doi.org/10. 3390/rs4061519.

Westoby, M. J., Brasington, J., Glasser, N. F., Hambrey, M. J., \& Reynolds, J. M. (2012). "Structure-from-Motion" photogrammetry: A low-cost, effective tool for geoscience applications. Geomorphology, 179, 300-314. https://doi.org/10.1016/ j.geomorph.2012.08.021.
Wetzel, R. G. (2001). Limnology: Lake and river ecosystems. San Diego: Gulf Professional Publishing.

Woodget, A. S., Carbonneau, P. E., Visser, F., \& Maddock, I. P. (2015). Quantifying submerged fluvial topography using hyperspatial resolution UAS imagery and structure from motion photogrammetry. Earth Surface Processes and Landforms, 40(1), 47-64. https://doi.org/10.1002/esp.3613.

Wu, C. (2013). Towards linear-time incremental structure from motion. In: 2013 international conference on $3 D$ vision (pp. 127-134). IEEE. https://doi.org/10.1109/3DV.2013.25.

Yucel, M. A., \& Turan, R. Y. (2016). Areal change detection and 3D modeling of mine lakes using high-resolution unmanned aerial vehicle images. Arabian Journal for Science and Engineering, 41(12), 4867-4878. https://doi.org/10.1007/s13369-0162182-7.

Zang, W., Lin, J., Wang, Y., \& Tao, H. (2012). Investigating smallscale water pollution with UAV remote sensing technology. In: World Automation Congress (WAC), 2012 (pp. 1-4).

Zolich, A., Johansen, T. A., Cisek, K., \& Klausen, K. (2015). Unmanned aerial system architecture for maritime missions. Design and hardware description. In: 2015 Workshop on Research, Education and Development of Unmanned Aerial Systems (RED-UAS) (pp. 342-350). IEEE. https://doi.org/10. 1109/RED-UAS.2015.7441026. 